\title{
REFLEXIONES SOBRE LA ADMINISTRACIÓN DE LA RENTA DEL TABACO DECIMONÓNICA EN CLAVE HISTÓRICO-JURÍDICA*
}

\author{
REFLECTIONS ON THE ADMINISTRATION OF $19^{\text {th }}$ \\ CENTURY TOBACCO REVENUE FROM A HISTORICAL \\ AND LEGAL PERSPECTIVE
}

Eduardo Galván Rodríguez

Universidad de Las Palmas de Gran Canaria

\section{RESUMEN}

Esta aportación analiza algunas de las diversas posibilidades planteadas para la administración del estanco español del tabaco durante el siglo XIX desde una óptica preferentemente histórico-jurídica. Desde la Historia del Derecho, en una España que comienza a transitar las vías del Estado constitucional, el trabajo aborda así la relación entre estanco y derecho, el desafío de la liberalización, la cuestión de la administración directa frente al arrendamiento o, por último, pero no menos importante, la relación entre estanco y contrabando.

Palabras clave: Estanco del tabaco, siglo XIX, administración.

\begin{abstract}
This contribution analyses some of the various possibilities facing the administration of the Spanish state monopoly of the tobacco industry during the nineteenth century from a historical-legal perspective. From the perspective of the History of Law, in a Spain that was beginning to progress towards a Constitutional State, this article addresses the relationship between the state monopoly on tobacco and the law, the challenge of liberalisation, the question of direct administration versus leasing, and, last but not least, the relationship between the state tobacco monopoly and contraband.
\end{abstract}

Keywords: Tobacco State monopoly $19^{\text {th }}$ century, administration.

\footnotetext{
*Trabajo realizado en ejecución del proyecto de investigación HAR2015-66142-R (MINECO/ FEDER) titulado "La configuración de los espacios atlánticos ibéricos. De políticas imperiales a políticas nacionales en torno al tabaco (siglos XVII-XIX)". La presente aportación es trasunto de la intervención del suscribiente en el 2nd International Workshop Political Cultures and Colonial Practices, celebrado en la Universitat Jaume I en septiembre de 2019 con el tema "Social Networks and Colonial Power in the Atlantic System of Tobacco".
} 


\section{RESUM \\ REFLEXIONS SOBRE L'ADMINISTRACIÓ DE LA RENDA DEL TABAC DECIMONÒNICA EN CLAU HISTÒRIC-JURÍDICA}

Aquesta aportació analitza algunes de les diverses possibilitats plantejades per a l'administració de l'estanc espanyol del tabac durant el segle XIX des d'una òptica preferentment històric-jurídica. Des de la Història del dret, a una Espanya que comença a transitar les vies de l'Estat constitucional, el treball aborda la relació entre estanc i dret, el desafiament de la liberalització, la qüestió de l'administració directa front a l'arrendamento, per últim, la relació entre estanc i contraban.

Paraules clau: Estanc del tabac, segle XIX, administració. 


\section{Proemio: el estanco Y el derecho}

"No estoy conforme". Estas son las últimas palabras que escuché de boca de mi padre. ' Así reafirmó su identidad cuando ya el cuerpo no obedecía sus órdenes. Órdenes y poder. Nuestro poder, nuestra autonomía sólo es posible cuando el cuerpo obedece nuestras órdenes. En caso contrario, pasamos a ser dependientes, en mayor o menor medida. Al cuerpo político le sucede algo parecido. La autonomía, la soberanía, el poder del cuerpo político sólo es posible cuando emite órdenes y puede obligar que sean cumplidas. El poder (en general y el político, en particular) sólo puede ser ejercido a través de dos medios: la fuerza y el derecho, vis y ius. Pero incluso la fuerza requiere del derecho para ser efectiva. La orden del soberano de ejercer la fuerza sólo es efectiva cuando las fuerzas (armadas o de seguridad) que deben ejercerla en la práctica reciben las órdenes correspondientes y las consideran como jurídicamente vinculantes. Dicho de otro modo, un soberano deja de serlo cuando pretende ejercer la violencia y no es obedecido; cuando sus mandatos jurídicos para el ejercicio de la

1 Eduardo Galván Ramírez falleció el 10 de marzo de 2020, cuatro días antes de que el Gobierno del Reino de España decretara el estado de alarma. Sirvan estas líneas de modestísimo homenaje y reconocimiento a una generación que, tras sufrir las inmensas privaciones de la Guerra, trabajó sin descanso y creó las condiciones socio-económicas que hicieron posible el advenimiento de una España constitucional e integrada en Europa. Sin su esfuerzo denodado y callado, día a día, el suscribiente, como tantos de su generación, simplemente no habría podido estudiar. 
violencia son ignorados precisamente por quienes deben imponerla. Quizá sea ocioso recordar aquella reflexión de Rousseau que advertía que hasta el más poderoso tiene que dormir $y$, cuando duerme, necesita que alguien vele su poder, necesita que el resto del cuerpo político continúe obedeciendo sus normas porque considera que son jurídicamente válidas.

Disculpen este contexto previo, necesario pues nos internamos en un terreno histórico-jurídico. Quien estas líneas suscribe, consciente de los padecimientos generales que el uso de la terminología jurídica infringe a la población, intentará huir de tales derroteros y procurará hacer realidad aquel deseo del ilustrado canario José Clavijo y Fajardo cuando, avanzado el siglo XVIII, pedía unas leyes claras, breves y sencillas; que hasta el último hombre del pueblo pueda conocer su contenido.

La relación entre estanco del tabaco y Derecho es constitutiva. El tabaco es una planta, no necesita al Derecho. Pero el estanco del tabaco sí. ${ }^{2}$ Sin Derecho no hay estanco del tabaco. Sin una norma jurídica que lo prescri$\mathrm{ba}$, el estanco no existe. El Estado utiliza una norma jurídica y su fuerza vinculante para monopolizar el cultivo, elaboración y comercialización del tabaco con el objeto de percibir una renta. De este modo, el Derecho aparece como un elemento constitutivo para el estanco.

El estanco del tabaco nace gracias a una norma. Y al estanco sólo puede derogarlo otra norma de igual o superior rango. Y en el siglo XIX hispano, el poder legislativo con capacidad suficiente para hacerlo está residenciado en las Cortes (unicamerales con la Constitución del 12 y bicamerales a partir del texto constitucional de 1837). Y sólo las Cortes podrían dictar

2 La presente temática es terra incognita, en particular desde la perspectiva histórico-jurídica. De ahí que no sea posible aportar bibliografía concreta sobre la cuestión en liza; más allá de las mismas aportaciones de un suscribiente que, por cortesía académica y la necesaria humildad científica, evita las autocitas. Desde una perspectiva general de historia económica, es de referencia obligada el reciente libro coordinado por LUXÁN, Santiago de, FIGUEIROA-REGO, João y SANZ ROZALÉN, Vicent (eds.) (2016), Tabaco y esclavos en los Imperios Ibéricos, Universidade Nova de Lisboa / Centro de História d'Aquém e d'Além Mar, Lisboa, que en páginas 9 a 15 incluye un balance historiográfico con abundantes referencias, a la que nos remitimos. Asimismo, también lo son el coordinado por SANZ ROZALÉN, Vicent, ZEUSKE, Michael y LUXÁN, Santiago de (coords.) (2019), Resistencia, delito y dominación en el mundo esclavo. Microhistorias de la esclavitud atlántica (siglos XVII-XIX), Editorial Comares, Granada; y el novísimo LUXÁN, Santiago de, FIGUEIROA-REGO, João y SANZ ROZALÉN, Vicent (eds.) (2019), Grandes vicios, grandes ingresos. El monopolio del tabaco en los imperios ibéricos (siglos XVII-XX), Centro de Estudios Políticos y Constitucionales, Madrid. 
una ley liberalizadora del tabaco, derogatoria del estanco (y de su renta). De ahí la necesidad de la perspectiva jurídica, concurrente con otras visiones (económica, política, cultural, etc.) igualmente esenciales para comprender el estanco del tabaco.

\section{ESTANCO FRENTE A LIBERALIZACIÓN}

Una intervención del diputado Istúriz en las Cortes del Trienio liberal, el 21 de junio de 1822, nos coloca en antecedentes de esta problemática. Para este parlamentario, "siempre será cierto que las ideas de estancos y de leyes prohibitivas no podrán jamás conciliarse con las de Constitución y libertad". Aproximémonos a esta problemática cuestión.

El Estado constitucional afirma la libertad individual y la propiedad privada como principios centrales del nuevo régimen. La Comisión Constitucional de las Cortes de Cádiz había asentado que la libertad consiste en poder hacer todo lo que no perjudica a la sociedad, ni ofende a los derechos de otro; mientras que la propiedad es el derecho que un ser humano tiene de gozar y disponer libremente de sus bienes y del fruto de su talento, de su trabajo y de su industria. Si ello es así, ¿̇cómo justificar que un individuo libre y propietario de su tierra no pueda cultivar en ella tabaco, ni elaborarlo, ni venderlo? ¿̇cómo justificar que un individuo libre no pueda comprar libremente la hoja de tabaco, elaborarlo y venderlo? ¿̇cómo justificar que un individuo libre no pueda comprar tabaco ya elaborado y venderlo en el libre mercado? ¿qué soluciones aporta el Estado constitucional español del XIX a esta contradicción?

La única solución jurídicamente coherente y sostenible parece pasar por el desestanco en la península del tabaco, lo que permitiría afirmar la libertad y la propiedad con carácter pleno. Sin embargo, el tabaco sólo estuvo desestancado de iure desde marzo de 1814 a mayo del mismo año y desde marzo de 1821 a julio del mismo año. Al margen de la iniciativa estatal, las juntas revolucionarias instauraron el desestanco de hecho desde marzo de 1820 a agosto del mismo año y desde septiembre de 1868 hasta febrero del año siguiente. Es decir, en total, durante todo el siglo XIX, encontramos unos ocho meses de desestanco de iure $y$, siendo muy generosos desde el punto de vista jurídico, unos veinte meses si incluimos el desestanco de facto; menos de dos años en este caso, menos de uno en el sentido estricto. Dicho de otro modo, si bien el poder legislativo no resolvió la contradicción más arriba planteada, las juntas revolucionarias lo hacían de inmediato por la vía de hecho.

En este punto, la cuestión es de hecho, más que de Derecho. La renta del tabaco facilita ingresos al Estado que éste no puede sustituir. Además, por 
si fuera poco, es preciso financiar las múltiples guerras (internas y externas) que asolan al Estado constitucional hispano a lo largo de todo el XIX. Es esclarecedor que la primera oportunidad de desestancar el tabaco aparece en medio de la guerra de Independencia, en la que se juega el ser o no ser del mismo orden político. Acordes con los principios liberales de partida, las impresiones iniciales son favorables al desestanco. El 2 de noviembre de 1811, el Ministro de Hacienda presenta una memoria a las Cortes en la que muestra los perivicios del estanco y defiende el comercio libre del tabaco. ${ }^{3}$ Los trabajos de la Comisión de Hacienda de la cámara lo avalan. ${ }^{4}$ Sin embargo, el tabaco ayuda a financiar el esfuerzo bélico y no llega el momento para adoptar una decisión definitiva. ${ }^{5}$

Resuelta la incertidumbre bélica a favor de las armas españolas, el 13 de marzo de 1814, las Cortes analizan un proyecto de Decreto sobre desestanco y derechos que pueden imponerse a los tabacos, que, en su primer artículo, deroga el estanco en "todas las provincias de la Monarquía española en ambos mundos"; artículo que es aprobado por unanimidad. ${ }^{6}$ Tras cierto debate, con idas y venidas a la Comisión en los días siguientes, el Decreto resulta aprobado. ${ }^{7}$ Pero ya es demasiado tarde. Antes de dos meses, Fernando VII deroga la obra constitucional. ${ }^{8}$

Con el Trienio aflora una nueva oportunidad para desestancar el tabaco. Varias localidades supusieron que la vuelta del régimen constitucional implicaba liberalizarlo, y así lo hicieron, para alarma de los responsables ministeriales del ramo. 9 Frente a este desestanco de hecho, el Ministro de Hacienda, admite que la falta de numerario impide liberalizar de inmediato, y pospone la decisión al momento de discutir el arreglo de las aduanas (rentas que, en principio, estaban destinadas a sustituir los ingresos generados hasta entonces por el estanco). ${ }^{10}$

3 Diario de Sesiones de las Cortes (DSC), 2 de noviembre de 1811, p. 2200.

4 DSC, 9 de marzo de 1812, pp. 2891-2892; DSC, 10 de marzo de 1812, p. 2898; DSC, 6 de julio de 1813, pp. 5625 ss; y DSC, 22 de enero de 1814, apéndice.

5 Gaceta de la Regencia de España e Indias, 2 de julio de 1811, p. 695; 22 de agosto de 1811 , p. 876 . Numerosos donativos procedentes de la isla de Cuba serán publicados en varios listados incluidos en los siguientes números de esta publicación.

6 DSC, 13 de marzo de 1814, pp. 112 ss.

7 DSC, 17 de marzo de 1814, p. 129.

8 Gaceta extraordinaria de Madrid, 12 de mayo de 1814, pp. 515-521.

9 Gaceta de Madrid, 22 de junio de 1820, p. 717.

10 DSC, 13 de julio de 1820, apéndice. 
La persistencia del desestanco de hecho desata un intenso debate parlamentario entre partidarios y detractores. ${ }^{11}$ Entre otros argumentos, estos sostienen que la libertad es incompatible con el monopolio estatal. Aquellos replican que los fondos procedentes de la renta del tabaco son necesarios precisamente para que el Gobierno pueda garantizar la libertad. Al final, la necesidad manda y las Cortes decretan la subsistencia del estanco. ${ }^{12}$ Ello no es óbice para que varias Diputaciones provinciales rechacen la medida, y para que la Comisión de Agricultura de la misma cámara apruebe un informe contrario al estanco en términos contundentes. ${ }^{13}$ La Comisión de Hacienda replica con un dictamen que mantiene las rentas estancadas por ahora, pero con reformas que las dejen "casi insensibles, despojadas de toda la odiosidad que en el día tienen" ${ }^{14}$ La presión liberalizadora fue de tal magnitud que, finalmente, queda decidido que el estanco del tabaco perdure sólo hasta el 1 de marzo del año siguiente.

Poco dura la alegría. El 8 de marzo el Ministro de Hacienda critica que "la liberalidad de los decretos últimos, habiendo hecho desaparecer rentas enteras... ocasiona vacíos considerables en la Hacienda, difíciles de suplir". ${ }^{15}$ Transcurren poco más de dos meses y la Comisión de Hacienda propone estancar nuevamente el tabaco. ${ }^{16} \mathrm{En}$ el debate consiguiente, el diputado Banqueri apoya la propuesta de la Comisión, pues "el comer de la tropa y cubrir las atenciones públicas no dan espera... sepan las Cortes que Constitución sin Hacienda no puede existir, pero Hacienda sin Constitución sí". Superado el debate parlamentario, un Decreto de 4 de julio de 1821 restablece y consolida el estanco del tabaco. ${ }^{17}$

Por si no estuviera claro, cuando las fuerzas absolutistas toman Madrid, la Regencia del Reino deja sin efecto las normas dictadas durante el Trienio liberal (incluidas las de "desestanco, libre comercio y alteración de los precios del tabaco y sal"), y restablece la normativa anterior. ${ }^{18}$ En el bando

11 DSC, 22 de julio de 1820, pp. 238 ss.

12 El Decreto es publicado con fecha de 6 de agosto de 1820 (DSC, 21 de octubre de 1820, p. 1820).

13 DSC, 7 de agosto de 1820, p. 853; DSC, 16 de agosto de 1820, p. 532; DSC, 20 de agosto de 1820, pp. 589 ss.; y DSC, 4 de octubre de 1820, p. 1398.

14 DSC, 9 de octubre de 1820, extraordinaria, pp. 1521 ss.

15 DSC, 8 de marzo de 1821, apéndice, pp. 177 ss.

16 DSC, 28 de mayo de 1821, pp. 1906 ss.

17 Gaceta de Madrid, 13 de julio de 1821, pp. 1083-1084.

18 Gaceta de Madrid, 17 de junio de 1823, p. 52. 
contrario, las Cortes fugitivas lanzan un último (e inútil) grito rectificador y, el 28 de junio de 1823, decretan que "el cultivo, venta y fabricación del tabaco queda en plena libertad desde primero de julio próximo". ${ }^{19} \mathrm{Es}$ conocido que, de nuevo, era demasiado tarde.

La nueva gran oportunidad liberalizadora llegará de la mano del Bienio progresista. Las Cortes Constituyentes inician su andadura un miércoles 8 de noviembre de $1854 .{ }^{20}$ En cuanto comienza el nuevo año, es presentada una proposición de ley desestancadora. ${ }^{21} \mathrm{~A}$ los pocos días, el Ministro de Hacienda, Madoz, subraya la rentabilidad de la renta del tabaco. ${ }^{22}$ Aviso inútil, pues aflora una nueva proposición de ley para suprimir esta renta. ${ }^{23}$ La posición de Madoz es contundente: "Deseo que conste que el Gobierno está resuelto a oponerse a este proyecto de ley" ${ }^{24}$ La presión sobre el Ejecutivo aumenta cuando la Comisión de Presupuestos dictamina que el Gobierno prepare "para un porvenir próximo y oportuno la transformación de la renta de tabacos en renta de aduanas", tras calificar el estanco como "negación de las buenas doctrinas económicas... insostenible bajo el punto de vista de la ciencia y la conveniencia pública". ${ }^{25}$ Sin embargo, la dura realidad pronto muestra que los deseos de la Comisión son vanos por ahora. Cuando un nuevo Ministro de Hacienda, presenta el proyecto de presupuestos del Estado mantiene la renta del tabaco. ${ }^{26}$

Sorprendentemente, antes de un mes, el Ejecutivo presenta un proyecto de ley para el desestanco del tabaco, que entraría en vigor el 1 de julio de 1857. ${ }^{27}$ La Comisión tardará más de seis meses en dictaminarlo (con votos particulares, uno de los cuales propone conservar el estanco "por aho$\left.\mathrm{ra}^{\prime \prime}\right) .{ }^{28}$ Nuevamente, será demasiado tarde para el desestanco. La siguiente

19 Gaceta Española, Cádiz, 18 de julio de 1823, pp. 351-353.

20 DSC, 8 de noviembre de 1854, p. 2.

21 DSC, 3 de enero de 1855, pp. 1108-1109; y DSC, 4 de enero de 1855, apéndice segundo.

22 DSC, 24 de enero de 1855, p. 1606.

23 DSC, 26 de enero de 1855, apéndice sexto.

24 DSC, 26 de enero de 1855, p. 1625.

25 DSC, 11 de julio de 1855, apéndice quinto.

26 DSC, 1 de octubre de 1855, apéndice décimo octavo; y DSC, 11 de octubre de 1855, p. 7088.

27 DSC, 9 de noviembre de 1855, apéndice cuarto.

28 DSC, 30 de junio de 1856, apéndice décimo noveno; y DSC, 1 de julio de 1856, apéndice vigésimo segundo. 
reunión de la cámara levanta acta del final del Bienio progresista. ${ }^{29}$ Una nueva ocasión perdida.

En los años siguientes, con los incrementos en la recaudación de la renta del tabaco, decrecen las esperanzas para los partidarios del desestanco. De tal modo que, el 16 de enero de 1862, el diputado Madoz recuerda que en la minoría progresista, "partidarios francos y abiertos somos del desestanco; pero vuelvo a decir y tómese nota de mis palabras, partidarios del desestanco de la sal y el tabaco, cuando el desestanco pueda hacerse sin llevar ninguna perturbación al Tesoro público". ${ }^{30}$ Al poco tiempo, la recaudación prevista de la renta llega nada menos que al millón de reales por día. ${ }^{31}$ Las voces favorables al desestanco desaparecen o guardan silencio.

Con el estallido de la Revolución en el 68 resuenan los ecos del Trienio liberal. Las juntas revolucionarias desestancan el tabaco, pero, calmado el furor revolucionario y tomado el control por el nuevo Gobierno en Madrid, el Presidente del Gobierno provisional ofrece un baño de realidad a los parlamentarios y les advierte que "la opinión y hasta la más vulgar prudencia reclaman imperiosamente economías, y nos lisonjeamos de que en este sentido llegaréis a tocar los últimos límites de lo razonable y lo posible" ${ }^{32}$ El necesario reconocimiento y apoyo internacional imprescindibles para el nuevo régimen, la revuelta en Puerto Rico (rápidamente sofocada) y el estallido de la guerra en Cuba obligan al Ejecutivo a poner los pies en tierra. Es preciso garantizar los ingresos cuanto antes. El Ministro de Hacienda apunta que "los estancos deben, sin duda alguna, desaparecer en un breve plazo; pero no es posible hacer esta reforma de un modo repentino y violento sin graves perjuicios para el Tesoro". ${ }^{33}$ Como si todo esto no fuera con él, el inagotable diputado José María Orense presenta una proposición de ley sobre desestanco de la sal y del tabaco. ${ }^{34}$ Cuando defiende su propuesta, Orense recuerda que ya lo hizo en las Constituyentes del Bienio progresista y que "ha sido uno de los constantes caballos de batalla que durante cincuenta años he sostenido defendiendo todas las libertades". ${ }^{35}$

29 DSC, 14 y 15 de julio de 1856, p. 14981; y DSC, Real Decreto de 3 de septiembre de 1856, pp. 14989-14991.

30 DSC, 16 de enero de 1862, p. 606

31 DSC, 3 de febrero de 1865 , p. 279

32 DSC, 11 de febrero de 1869, p. 2.

33 DSC, 24 de febrero de 1869, apéndice.

34 DSC, 2 de marzo de 1869, apéndice quinto.

35 DSC, 5 de marzo de 1869, pp. 321 ss. 
Como aviso a navegantes, adelanta que "pasma ver la repugnancia que hay aquí a toda medida liberal; pasma ver con qué facilidad se retrocede; pasma ver cómo los hombres sostienen una cosa cuando no están en el poder y cómo luego practican otra muy distinta en los bancos ministeriales".

A Orense le responde el Ministro de Hacienda, quien ruega que la proposición de ley pase a la Comisión de Presupuestos. Contrariado, Orense rechaza que pase a esa Comisión, y propone formar una comisión ad hoc compuesta de siete diputados, pues, de pasar a la de Presupuestos, eso "es lo mismo que aplazar la resolución del asunto"; sería como "seguir el sistema de Bertoldo, que cuando le condenaron a ser ahorcado decía: 'Yo estoy conforme con que me ahorquen, pero que me dejen escoger el árbol'. No, señores, las cosas se hacen o no se hacen". El responsable ministerial insiste en su postura, dado que "se trata de una renta que produce ingresos, que por lo tanto ha de figurar en el presupuesto de ingresos y que, por consiguiente, como trata de abolirse, ha de tomarlo en cuenta indefectiblemente la Comisión de Presupuestos". Enconada la cuestión, el Ministro cede y aclara que "no tengo inconveniente, pues no insisto en que pase a la de Presupuestos". El 9 de marzo es nombrada la Comisión sobre el desestanco del tabaco y de la sal. ${ }^{36}$

Ello no impide que el Ministro de Hacienda presente el proyecto de ley de presupuesto de ingresos para el año económico 1869-1870 en la sesión de 19 de abril. El responsable ministerial advierte que la desaparición de la renta del tabaco "como tributo nadie puede aconsejarla, mientras que la desaparición como estanco puede ser conveniente, pero no dentro de los límites del ejercicio futuro, atendida la importancia de las reformas que se proponen". ${ }^{37}$ En todo caso, si las Cortes Constituyentes apuestan por el desestanco, sugiere que sea efectivo a partir del 1 de julio de 1870, con el objeto de prepararlo como exige la necesidad de "evitar todos los conflictos de una transición brusca y salvar los recursos del Tesoro", y para que "al cesar la manufactura oficial, las clases jornaleras que en ella encuentran salario puedan sin dificultad tener colocación en las fábricas y talleres de los particulares". Con harta previsión, el Ministro adelanta en el presupuesto el texto del proyecto de ley de desestanco del tabaco, con efectos a partir del 1 de julio, y como resultado de sus trabajos de común acuerdo con la Comisión parlamentaria designada al efecto, tal y como veremos a continuación. ${ }^{38}$

36 DSC, 9 de marzo de 1869, p. 394.

37 DSC, 19 de abril de 1869, apéndice primero.

38 DSC, 19 de abril de 1869, p. 1162. 
La Comisión sobre el desestanco del tabaco y de la sal publica su dictamen al día siguiente. El texto reconoce que "los monopolios del Estado no podían encontrar defensores del sistema opresivo que envuelven entre quienes aspiran a que la libertad fecunde todas las industrias y el Gobierno concentre sus fuerzas en la alta misión de hacer que reine la justicia en todas las esferas sociales". ${ }^{39}$ Sin embargo, exige dos condiciones para que esta reforma sea estable: a) que "no quebranten más las fuerzas, sobrado débiles ya, de la Hacienda, ni dejen un vacío en el Tesoro imposible de llenar"; b) que "se asegure sin perturbaciones el regular abastecimiento de los mercados, evitando crisis que produzcan manifestaciones contra las medidas adoptadas y den pretexto para su demolición". El cumplimiento de ambas precondiciones podría recomendar "alguna tregua para realizar la reforma y el establecimiento de un período transitorio más o menos breve". Con el acuerdo de la Comisión con el Ministro de Hacienda "respecto a la inmediata extinción del monopolio de la sal, el parecer es unánime" y será desestancada el 1 de enero de 1870. En cambio, el tabaco deberá esperar al 1 de julio del mismo año.

Este dictamen de la Comisión cuenta con un voto particular del diputado Servando Ruiz Gómez (Director de Rentas Estancadas). El discrepante disiente porque "corren grave peligro la prosperidad de la Nación, las conquistas revolucionarias y hasta las reformas económicas realizadas o en proyecto (especialmente la relativa al desestanco de la sal) si se destruye de una vez y casi en un sólo día nuestro sistema rentístico y se procede inmediatamente a desestancar el tabaco, que constituye una parte importante de las rentas del Estado y, por tanto, es una firmísima garantía de nuestro crédito económico, dentro y fuera de España". Para evitarlo, plantea diferir la decisión "hasta nivelar sólidamente los presupuestos con ingresos ordinarios y fijos". El Director reconoce que "el estanco del tabaco no es popular, pero para mi es patriótico sostenerlo". ${ }^{40} \mathrm{Al}$ mismo tiempo, recuerda que el tabaco no es "una necesidad de la vida humana... es una especulación sobre un vicio de los tiempos modernos, y como tal vicio puede la administración, si no combatirlo, considerarlo como la contribución suntuaria que más abundantes productos procura a todos los Gobiernos". Contra este criterio, y en nombre de la Comisión, el diputado Baeza sostiene que "el principio del estanco elevado a sistema es el monopolio, y que el monopolio, ejercido por el Estado a su vez en la esfera industrial, es la anulación del ejercicio de los derechos individuales". Reprocha al 
discrepante que se haya colocado "en el mismo terreno donde han estado siempre atrincherados los constantes partidarios del estanco". Es más, defiende que "el desestanco es la única salvación de la renta, porque si no se lleva a efecto continuará disminuyendo irremisiblemente".

Tácticamente, los partidarios del desestanco aumentan la presión con una enmienda al dictamen de la Comisión para que el desestanco comience el 1 de enero de 1870, dado que "con siete meses que median desde esta fecha... tiene tiempo la administración para preparar el cambio de sistema y realizar todas las existencias de tabacos manufacturados". ${ }^{41}$ El Director de Rentas no ceja e insiste en que no quiere "el monopolio, a pesar de que estoy sosteniendo uno, que es el del Estado; porque después de todo, yo creo que el monopolio de los particulares es más tiránico que el del Estado... Por eso quiero mejor el monopolio del Estado que el de un particular... ¿ Defiendo yo por esto el monopolio? No, lo que defiendo son las rentas, ni más ni menos, y las defiendo por la mala situación en que nuestra Hacienda está colocada". ${ }^{42}$

En la misma sesión interviene su superior jerárquico, el Ministro de Hacienda, quien subraya que "el estanco y los derechos individuales son dos cosas incompatibles, que se rechazan". Abunda en esta idea y plantea que, una vez aprobada la Constitución, el estanco choca con varios principios constitucionales, como, por ejemplo, la inviolabilidad del domicilio, que hace inviable en la práctica el desarrollo de las actuaciones inspectoras contra el contrabando. Constatada esta contradicción del estanco con el orden constitucional, el responsable ministerial desarrolla su discurso en torno a las bondades del desestanco, gracias al cual, sostiene nada menos que "sin peticiones humillantes, sino por una ley de la historia y de los sucesos mismos, Gibraltar volverá a ser español por el simple hecho del desestanco, de un sistema arancelario o aduanero más perfecto". Además, añade la imposibilidad material de sostener el estanco cuando el tabaco corre libre por Portugal, Gibraltar y las provincias vascongadas. En consonancia, solicita a la cámara que deseche el voto del Director de Rentas. No por ello deja caer a su subordinado, bien al contrario, elegante, reconoce "la amistad que tengo... habiéndole dejado en completa libertad para defender su voto, con el que ha dado una prueba de su independencia, de lo arraigado de sus convicciones y de su buen deseo, puesto que le encamina a procurar recursos al Tesoro". Nuestro Director había presentado su

41 DSC, 28 de mayo de 1869, apéndice segundo.

42 DSC, 31 de mayo de 1869, pp. 2447 ss. 
dimisión al conocer la posición de su superior, sin embargo, su Ministro le convence de que no abandone el cargo. Finalmente, el voto particular del Director de Rentas Estancadas, diputado Ruiz Gómez, queda desechado y no es tomado en consideración por 136 votos en contra frente a sólo 38 votos favorables. Punto para el desestanco (por ahora).

En este tenso ambiente, el 14 de junio es sancionada la ley sobre desestanco de la sal..$^{43}$ Mientras tanto, el tabaco aún espera su turno. Ocho días después, el diputado Caro manifiesta su oposición a que la discusión sobre el dictamen permanezca suspendida y suplica a la Mesa "que se sirva ponerlo a discusión antes que otros proyectos que no son tan importantes, con tanta más razón cuanto que ya se ha discutido el voto particular del Sr. Ruiz Gómez relativo a este asunto". ${ }^{44}$ Interviene el diputado Becerra y aclara que suspender la discusión ha sido una decisión de la Mesa, no de la Comisión que "no tiene inconveniente en que se discuta lo antes posible, bien al contrario, lo desea".

Algo sucede fuera de guión. En el debate presupuestario, el Ministro de Hacienda matiza que la renta del tabaco no es producto de "una contribución... no pagándola sino los fumadores, puesto que los que no fuman no van al estanco, ni pagan esa contribución". ${ }^{45} \mathrm{Y}$ parece desechar sus anteriores manifestaciones, al añadir que, de resultar aprobado el desestanco, "tengo la creencia de que para fumar lo que ahora se da en el estanco, tendrá que pagarse más caro". La respuesta del diputado Orense es inmediata. El marqués de Albaida suplica a la Comisión que entiende en el proyecto del desestanco del tabaco "a fin de que influya con el Sr. Ministro de Hacienda para llevar a pronto término este asunto... El tiempo pasa y el proyecto no llega a ser ley". ${ }^{46}$ Tanto la Mesa como la Comisión expresan sus buenos deseos en tal sentido.

Pero son sólo buenos deseos. La rectificación de la postura ministerial no tarda en llegar. Acontece cuando el mismo Ministro de Hacienda presenta el proyecto de ley sobre presupuestos del Estado para el año económico 1870-1871, donde apunta que "el desestanco de la sal, la abolición de los portazgos y barcajes y la supresión del impuesto de consumos iniciaron un período de transformación de nuestro sistema tributario durante el cual son difíciles los cálculos. Llevar bruscamente a las contribuciones directas sumas enormes que antes satisfacía indirectamente el país es una empresa

43 DSC, 14 de junio de 1869, apéndice segundo.

44 DSC, 22 de junio de 1869, pp. 2963-2964.

45 DSC, 29 de junio de 1869, p. 3320.

46 DSC, 30 de junio de 1869, p. 3346. 
difícil, sin duda, pero realizable". ${ }^{47}$ Por lo que toca al tabaco, añade que "para facilitar esta sustitución, para asegurar el éxito de las reformas, el Gobierno cree conveniente no proseguir la transformación de los impuestos indirectos". La consecuencia es la esperada. El Ejecutivo "propone, por lo mismo, la continuación del estanco del tabaco, que tan pingües rendimientos proporciona al Tesoro, porque al prescindir de este monopolio sería necesario recargar las contribuciones directas". Suma otras consideraciones: "Dada la situación del país, abrumado bajo el peso de tantas cargas; dada la situación del Tesoro, claramente expuesta a la consideración de las Cortes, el Ministro de Hacienda considera que sería una injusticia en el orden moral y gravísima imprevisión en el político abaratar una planta exótica, artículo de lujo para el hombre, encareciendo, en cambio, las producciones del suelo, alimento indispensable y riqueza principal de una nación agrícola".

Comienza el nuevo año. Hace nueve meses que está publicado el dictamen de la Comisión. Y ahí ha quedado el recorrido parlamentario, tras haber superado el controvertido voto particular. En la sesión de 19 de febrero de 1870, el diputado Figueras pregunta al Ministro de Hacienda "si está dispuesto a llevar adelante el desestanco del tabaco". ${ }^{48}$ Figuerola -aún Ministro del ramo-, le responde que "el tabaco continúa estancado. La opinión del Ministro de Hacienda es bien conocida, siempre ha sostenido la conveniencia del desestanco y no ha cambiado de parecer, pero son tantas las atenciones que pesan sobre la Cámara que han impedido al Sr. Presidente anteponer la discusión de ese proyecto a la de otros que eran mucho más urgentes". Transcurren más de dos meses y el diputado Rebullida recuerda que aún está pendiente la discusión del dictamen y ruega a la Mesa "se sirva mandarla continuar". ${ }^{49}$ El Vicepresidente le responde que la Mesa "tomará la determinación que crea oportuna".

El 14 de mayo, la Comisión de Presupuestos publica su dictamen sobre el de ingresos del Estado para el ejercicio económico 1870-1871, e introduce una rebaja de casi cien millones de pesetas, de acuerdo con el Ministerio de Hacienda.$^{50}$ Los ingresos previstos por la renta del tabaco ascienden a 83.1 12.500 pesetas, cantidad conforme con el proyecto gubernamental. A los diez días, el Ministro de Hacienda presenta una memoria sobre la

47 DSC, 29 de octubre de 1869, apéndice primero.

48 DSC, 19 de febrero de 1870, p. 5921.

49 DSC, 27 de abril de 1870, p. 7492.

50 DSC, 14 de mayo de 1870, apéndice tercero. 
situación del ramo. ${ }^{51}$ En ella critica duramente la decisión adoptada en 1866 al permitir la libre venta de las labores traídas de las Antillas, punto a partir del cual cifra el descenso en los rendimientos, pues "a la sombra de ella ha debido cometerse un exagerado y escandaloso fraude muy difícil de evitar, porque no cabe aquí más que uno de dos sistemas: o la libertad absoluta, o el monopolio; pero no el estanco o el desestanco a medias que tienen todos los inconvenientes del monopolio sin ninguna de las ventajas de la libertad". A pesar de esta situación de partida, el responsable ministerial entiende que las reformas gubernamentales de esta renta han permitido que "no decaiga y mantener viva la esperanza de su progreso, mientras no sea posible proceder al desestanco de este artículo, que es uno de los propósitos que animan al Gobierno".

Pasan seis meses más y el 26 de diciembre, quien fuera Director de Rentas Estancadas, el diputado Ruiz Gómez, defensor de mantener la renta del tabaco, que "sostuve sin apoyo, quedándome casi sólo, pero en la buena compañía de treinta diputados que conmigo votaron", subraya que "la renta del tabaco no ha sido abolida. Tan lejos de eso, como que es hoy una de las esperanzas del señor Ministro de Hacienda, fundando en ella nada menos que una operación de crédito". ${ }^{52}$ Contundente aparece el Ministro de Hacienda (ahora Moret y Prendergast), quien aclara que "en el tabaco tiene que llegar el momento en que la renta no se pueda reformar o en que haya sobrantes en el presupuesto para hacer desde luego el desestanco... [pero es preciso] o el desestanco o el estanco; el medio estanco no puede aceptarse de ningún modo, y el estanco, si yo estoy aquí, vendrá, pese a quien pese, mientras no llegue el caso del desestanco". La legislatura concluyó con la sesión de 2 de enero de $1871 .^{53}$

Y Moret cumple su palabra. Con anterioridad al comienzo del siguiente período legislativo, el Gobierno aprueba un Decreto de 26 de enero de 1871 que deroga el dictado el 20 de abril de 1866 por el que quedaba autorizada la libre introducción y venta de tabacos elaborados procedentes de Cuba y Puerto Rico. ${ }^{54}$ Recordemos que aquel levantamiento parcial del estanco era diagnosticado como el causante del incremento del fraude y de la disminución constante de los ingresos brutos de la renta, que había quebrado una tendencia creciente mantenida durante años. Ahora el Mi-

51 DSC, 24 de mayo de 1870, apéndice segundo.

52 DSC, 26 de diciembre de 1870, pp. 9446 ss.

53 DSC, 2 de enero de 1871, pp. 9577-9579.

54 Gaceta de Madrid, 27 de enero de 1871, p. 209. 
nistro ciega esta posibilidad y acaba con "el medio estanco", tal y como había anunciado en sede parlamentaria los últimos días del año anterior. De este modo, la libre introducción y venta de estos tabacos antillanos queda prohibida a partir del 31 de mayo.

Ante el documento gubernamental que mantiene el estanco, el diputado Orense reitera la necesidad de desestancar, pues "proporcionará trabajo a 100.000 familias, en lugar de mantener sin hacer nada a 20.000 estanqueros". El marqués enfatiza que "es una vergüenza y un escándalo... llamarse economistas y sostener el estanco del tabaco y mantener las loterías y hacer lo que hacen es una cosa para mí verdaderamente inconcebible" ${ }^{55}$ La presión liberalizadora aumenta. El 25 de mayo, varios diputados presentan una proposición de ley para que se declare libre el cultivo, elaboración y venta del tabaco desde el 1 de julio del mismo año. ${ }^{56}$ La propuesta aparece limitada a este objeto (art. 1); a fijar los derechos de introducción del tabaco en sus distintas modalidades (art. 2); a ordenar la venta en pública subasta de los edificios y enseres destinados a la elaboración antes del 1 de enero de 1872, verificándose el pago de los adquirentes en siete plazos semestrales (art. 3) e indicar al Ministro de Hacienda que presente inmediatamente en las Cortes las tarifas de contribución directa que habrán de pagar los industriales y vendedores de tabaco (art. 4). El diputado que encabeza la propuesta la funda en que "es la aspiración del pueblo español desde hace más de un siglo" y en que "los partidos liberales en sus diferentes fracciones han defendido siempre el principio del desestanco del tabaco con todas sus consecuencias". ${ }^{57}$

La Comisión nombrada para dictaminar acerca de esta proposición de ley sobre liberalización del tabaco presenta su dictamen el 7 de junio, $y$, con un sorprendente cambio de criterio, parte del presupuesto de que los economistas "cuando consideran la realidad de las cosas... admiten la necesidad de recurrir a todas las formas del impuesto, sin exceptuar el monopolio, y ninguno tiene condiciones más favorables para su establecimiento que el del tabaco, que es en el fondo una contribución voluntaria establecida sobre el consumo de una materia que no es precisa para la existencia del hombre y que, por no producirse hoy en la Península, es fácil y poco costoso establecer su estanco" ${ }^{\prime 58}$ Cuán lejos de las consideraciones favorables al desestanco sostenidas por las juntas revolucionarias y las

55 DSC, 19 de mayo de 1871, pp. 950-951.

56 DSC, 25 de mayo de 1871, apéndice sexto.

57 DSC, 30 de mayo de 1871, p. 1280.

58 DSC, 7 de junio de 1871, apéndice tercero. 
Cortes Constituyentes. La Comisión admite que el desestanco conllevaría "la pérdida total de estos ingresos" y que la sustitución por los derechos de aduana no llegaría "jamás a compensar tan enorme perjuicio, irreparable y de funestísimos resultados para la Hacienda, cuya triste situación nadie desconoce". A la vista de tales consideraciones "y de otras que se omiten en gracia de la brevedad", la Comisión propone un proyecto de ley con artículo único que reza: "Se mantendrá en su forma actual el estanco del tabaco, sin perivicio de adoptar cuantas medidas sean conducentes al desarrollo y crecimiento de esta renta pública". Casualidades de la vida, el Presidente de la Comisión es nuestro conocido diputado Servando Ruiz Gómez, defensor casi en solitario de la renta del tabaco con ocasión de los debates de las Cortes Constituyentes. Las esperanzas de los partidarios del desestanco parecen esfumarse. Otra oportunidad histórica desaprovechada. Será la última.

\section{ADMINISTRACIÓn DIRECTA FRENTE A ARRENDAMIENTO}

"Constitución sin Hacienda no puede existir, pero Hacienda sin Constitución sí". Estas son las palabras reveladoras del diputado Banqueri en la sesión de Cortes del 28 de mayo de 1821. El examen de las memorias, los estados, apéndices e informes presentados por el Ministerio de Hacienda y la Dirección General de Rentas atestigua que la renta experimenta valores crecientes de recaudación bruta a lo largo del siglo XIX (salvo ocasionales y fragmentarias bajadas ya mencionadas). Durante casi la totalidad de la centuria decimonónica, el estanco del tabaco estuvo bajo administración directa del Estado.

Una administración directa que cada vez recaudaba más y que arrastra una inmerecida mala fama de representar aposento propicio al clientelismo político que permite agraciar con puestos de trabajo inútiles a sujetos políticamente cercanos y de toda laya. Analizados los datos presupuestarios, resulta que los gastos de personal sólo alcanzan entre un 10 y un 15 por ciento de los gastos reproductivos de la renta, en una horquilla mantenida a lo largo de la centuria. Estos mismos datos evidencian que el mayor volumen de gastos de generación de la renta corresponde a la compra de la materia prima, y es ahí (en la compra del tabaco, fundamentalmente Virginia, Kentucky o Brasil) también donde suelen quedar localizados los casos de corrupción más llamativos denunciados ante la opinión pública.

Pero la administración directa funciona, con rendimientos crecientes. Lo recaudado por renta del tabaco asciende desde los 94 millones de reales del año 38, hasta los casi 143 millones del año 1846.59 Analizados los 
gastos de generación de la renta y los ingresos para el erario público entre los años 1845 y 1854, resulta siempre un rendimiento creciente de los ingresos que nos lleva a superar sobradamente los 200 millones en el año $54 .{ }^{60}$ En menos de veinte años, los ingresos han sido duplicados. Mientras tanto, los gastos de generación oscilan entre los casi 42 millones de los años 49 y 50, hasta los 81 millones del año 47, estando la media en torno a los 55 millones (los datos arrojan un 39 por ciento de media de gastos reproductivos en el período analizado).

Las cifras oficiales para el período 1870 a 1886 evidencian también que el porcentaje de beneficio para el Estado obtenido gracias a la administración directa de la renta del tabaco es de una media superior al 60 por ciento, con la obtención de un producto íntegro creciente que comienza en los poco más de 61 millones de pesetas ingresados en el primer ejercicio, hasta llegar a los casi 132 millones en el último, esto es, en unos quince años el producto íntegro para el Estado es más del doble. ${ }^{61}$

Frente a algún intento particular de arrendar la renta del tabaco, el Ministro de Hacienda manifiesta en sede parlamentaria, el 5 de noviembre de 1844, que "el Gobierno debe administrar y, si no sabe administrar, debe dejar este banco (el reservado para asiento de los miembros del Ejecutivo en las cámaras). Desde el momento que confiesa que un tercero tiene más medios para administrar, debe dejar el puesto". ${ }^{62}$

Doce años después, un 17 de marzo de 1856, otro Ministro de Hacienda reitera que el arrendamiento es "la degradación de todo Gobierno existente, es la negación de la autoridad pública y es imposible que haya ningún Gobierno que, apreciándose en algo, pueda tolerar semejante sistema, que lleva en pos de sí la ruina de los pueblos y el desprestigio del Gobierno, y que priva a este hasta de los medios de gobernar". ${ }^{63}$

Pese a esta posición, en general, favorable a la administración directa (y cuyos beneficios la refrendan), ciertos grupos de intereses apuestan por arrendar la renta del tabaco. Uno de ellos, del que forma parte el marqués de Salamanca, tendrá éxito antes de que el siglo XIX afronte su segunda mitad, aunque no por mucho tiempo. El 20 de febrero de 1844, el Gobierno aprueba las bases que regirán el arrendamiento. Pero, una vez adjudicado, el Gobierno lo rescinde al poco tiempo, lo que, el 4 de noviembre, pro-

60 DSC, 20 de octubre de 1855, apéndice primero, pp. 7465-7472.

61 DSC, 3 de diciembre de 1886, apéndice tercero.

62 DSC, 5 de noviembre de 1844, pp. 276 ss.

63 DSC, 17 de marzo de 1856, pp. 11712-11714. 
voca el duro reproche del mismo marqués de Salamanca desde su escaño como parlamentario (aunque no esconde su interés personal en la empresa adjudicataria del arrendamiento). ${ }^{64}$

Finalmente, la posición auspiciadora del arrendamiento encuentra un clima favorable cuando el siglo casi llega a su fin (y, por cierto, cuando la esclavitud ya había sido abolida por Decreto de 7 de octubre de 1886). Es posible que fuera la necesidad de introducir nueva maquinaria, necesaria para adaptarse a nuevas demandas del mercado y que requería una notable inversión, la que pudo propiciar el cambio de la administración directa de la renta a su arrendamiento en el frontispicio del último decenio del siglo XIX. Una ley de 22 de abril de 1887 autoriza al Gobierno para arrendar el monopolio. ${ }^{65}$ Parece ser que la falta de licitadores interesados provoca que el Banco de España (entidad privada por entonces) sea el adjudicatario del contrato, en virtud de Real Decreto de 10 de junio, con cierta polémica parlamentaria posterior. ${ }^{66}$

\section{LEY FRENTE A CONTRABANDO}

El contrabando es la negación de la ley y supone un cuestionamiento permanente de su aplicación práctica. Como en otros aspectos, el Trienio liberal es un semillero de aportaciones parlamentarias que apuntan a los ejes centrales de nuestra problemática. Un 29 de mayo de 1821, el diputado Urruela recuerda que "cuando la ley se opone al hombre, el hombre va contra la ley" ${ }^{67}$ Un creciente consumo del tabaco, especialmente entre las clases más humildes, a quienes calma el hambre y el frío, crea un clima propiciatorio para saltar los rígidos lindes del monopolio estatal. El diputado Moreno Guerra apunta que este fenómeno ilegal está provocado por el hecho de que "la Nación española ha tenido siempre un odio eterno al estanco del tabaco, lo cual ha aumentado infinito el número de contrabandistas $y$, por consiguiente, de ladrones, porque de contrabandista descaminado a ladrón no hay más que un paso". ${ }^{68}$

64 DSC, 4 de noviembre de 1844, p. 260.

65 Gaceta de Madrid, 23 de abril de 1887, pp. 201-203; y DSC, 25 de abril de 1887, apéndice primero.

66 Gaceta de Madrid, 12 de junio de 1887, pp. 655-656; DSC, 22 de junio de 1887, p. 3804; y DSC, 23 de junio de 1887, pp. 3871-3872.

67 DSC, 29 de mayo de 1821, pp. 1929 ss.

68 DSC, 22 de julio de 1820, 238 ss. 
Más arriba sosteníamos que el Derecho es un elemento constitutivo del estanco del tabaco. Sin embargo, el Derecho no es suficiente para que el estanco sea eficaz. La historia de nuestro Derecho acredita de modo fehaciente que una cosa es la norma y otra bien distinta su cumplimiento. Y la Gaceta de Madrid recoge abundantísimos testimonios que conforman un goteo incesante de incautaciones absolutamente incapaces de acabar con el contrabando.

Aproximadamente, las cifras suelen coincidir en que un tercio del tabaco consumido en la Península procede del contrabando. Y es que el tabaco de contrabando, en general, es de mejor calidad y no sufre las dificultades de distribución que el estancado, está disponible con mayor facilidad. Además, el contrabando es una actividad rentable y es una salida económica para la que no es necesario un gran capital inicial, abierta, por tanto, a gentes de toda extracción social. Encima, el contrabandista goza de prestigio social, está facilitando un bien de consumo extendido de mejor calidad y a mejor precio. A ello es preciso sumar, desde la perspectiva estatal, los costes que conlleva la persecución y castigo de los contrabandistas y la pérdida de brazos útiles para sectores productivos que conlleva (tanto los resguardos, como los propios delincuentes). Y siempre presente cuando una actividad ilegal está suficientemente extendida, aflora la corrupción y el consiguiente desprestigio de autoridades ( $y$, con ellas, de la misma capacidad prescriptiva de las normas jurídicas). Durante todo el siglo, es palpable la incapacidad de las normas jurídicas como instrumento para frenar la actividad delictiva del contrabando, a pesar de múltiples reformas legales que chocaron siempre de frente con el muro de la realidad. Conviene recordar que, en última instancia, la Ley, sin una conciencia social que la respalde, suele devenir inútil.

Volvemos así a las reflexiones del principio de este trabajo. Poder, violencia y derecho, vis y ius. Si algún fenómeno pone en evidencia la problemática relación entre ambas realidades es precisamente el contrabando, que implica la violación reiterada de las normas por aquellos que están obligados a cumplirlas, así como por aquellos que están obligados a hacerlas cumplir; y cuyas resultas pueden llegar al punto de subvertir el propio orden político, de sustituir al titular del poder. Entre otros ejemplos históricos conocidos, la experiencia palmaria de multitud de Estados frente al tráfico de drogas exime de más palabras. 